\title{
Kepemimpinan Kepala Sekolah dalam Pengelolaan Ekstrakurikuler di MI Nahdatul Ulama Sumber Agung
}

\author{
Submitted: 6 Oktober $2021 \quad$ Revised: 7 Oktober $2021 \quad$ Publish: 9 Oktober 2021
}

Syahri

Sekolah Tinggi Ilmu Tarbiyah NU Sumber Agung OKU Timur smsyahri007@gmail.com

\begin{abstract}
Extracuricular is needed by the education unit as a forum to develop the interests and talents of learners. The purpose of this study is how the role of the principal's leadership in the sustainability of extracurricular management at MI Nahdatul Ulama Sumber Agung. The research methods used in this study are qualitative, data sources through interviews, observations, and documentation. The results of this study are 1) The process of managing the cocurricular by the principal at MI Nahdatul Ulama Sumber Agung is carried out from the formulation, formulation, utilization, to the stage of evaluation and control of activities. 2) The obstacles faced in the extracurricular management of MI Nahdatul Ulama Sumber Agung are the difficulty of getting competent supervisors according to the field, sometimes difficulty to get infrastructure, and also obstacles in motivating learners to continue to be excited to follow the activities. 3) The result of the principal's leadership in managing extracurriculars at MI Nahdatul Ulama Sumber Agung is the interest and talent of students can be included in the race.
\end{abstract}

Keywords: Extracurricular, Head Master, Leadership, School,

\begin{abstract}
Abstrak
Ekstakurikuler dibutuhkan oleh satuan pendidikan sebagai wadah mengembangkan minat dan bakat peserta didik. Tujuan dari penelitian ini adalah bagaimana peran dari kepemimpinan kepala sekolah dalam kerberhasilan pengelolaan ekstrakurikuler di MI Nahdatul Ulama Sumber Agung. Metode penelitian yang digunakan dalam penelitian ini adalah metode kualitatif, sumber data melalui wawancara, observasi, dan dokumentasi. Hasil dari penelitian ini adalah 1) Proses pengelolaan ekrakurikuler oleh kepala sekolah di MI Nahdatul Ulama Sumber Agung dilakukan dari perencanaan.perumusan, pengadaaan, hingga tahap evaluasi dan kontrol kegiatan. 2) Kendala-kendala yang dihadapi dalam pengelolaan ekstrakurikuler MI Nahdatul Ulama Sumber Agung adalah sulitnya mendapatkan pembimbing yang kompeten sesuai bidang, kadang sulit mendapatkan prasarana, dan juga kendala dalam 132
\end{abstract}

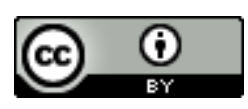

This work is licensed under a Creative Commons Attribution 4.0 International License 


\section{AL-Azkiya: JURHAL LYHAH PEIDIDIKAK YIISD \\ ISSI: Print (2145-7653) Online (2527-8170) \\ Vol. 6 No.2 2021 \\ D01 10.32505/al-akiva.1092.3013}

memotivasi peserta didik agar terus bersemangat mengikuti kegiatan. 3) Hasil dari kepempinan kepala sekolah dalam mengelola ekstrakurikuler di MI Nahdatul Ulama Sumber Agung adalah minat dan bakat siswa bisa diikutsertakan dalam perlombaan.

Kata kunci : Ekstrakurikuler, Kepemimpinan, Kepala Sekolah.

\section{PENDAHULUAN}

Pendidikan merupakan kebutuhan pokok setiap masyarakat karena melalui pendidikan, karakter seseorang akan terbentuk sehingga dapat meningkatkan martabat dan wibawanya. Melalui pendidikan pula potensi yang ada dalam diri seseorang dapat dikembangkan, sebab pendidikan diupayakan secara sadar dan terencana untuk mewujudkan suasana belajar dan proses pembelajaran agar peserta didik secara aktif mengembangkan potensi dirinya untuk memiliki kekuatan spiritual keagamaan, pengendalian diri, kepribadian, kecerdasan, ahlak mulia serta keterampilan yang diperlukan dirinya, masyarakat, bangsa dan Negara. Pendidikan dapat ditempuh melalui jalur formal maupun nonformal. Sekolah merupakan jalur pendidikan formal, yang memfasilitasi peserta didik untuk mendapat ilmu, pengalaman baru, berinteraksi dengan warga sekolah, mengembangkan potensi yang ada dalam dirnya, dan lain sebagainya.

Peserta didik memiliki peran yang besar dalam proses dan kemajuan sekolah. Tidak hanya peserta didik, warga sekolah seperti kepala sekolah, wakil kepala sekolah, guru, karyawan juga saling bekerja sama untuk mencapai visi dan misi dari sekolah tersebut. Semua aspek tersebut harus dikelola dengan tepat agar visi dan misi yang dicapai sesuai dengan yang direncanakan. Kepala sekolah adalah ujung tombak untuk pencapaian kesuksesan dan kemajuan dari sebuah sekolah yang dipimpinnya.

Pencapaian setiap sekolah tentunya tidak sama. Ada sekolah yang lebih mementingkan pencapaian akademik, namun ada juga yang mementingkan

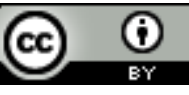


pencapaian nonakademik, misalnya ada sekolah yang menonjolkan penataan lingkungan sekolahnya (adiwiyata). Setiap sekolah berhak mengembangkan kelebihan maupun keunikan yang menjadi ciri dari sekolah tersebut. Termasuk menonjolkan kegiatan ekstrakulikuler.

Kegiatan ekstrakurikuler merupakan kegiatan pembinaan kesiswaan yang dilaksanakan diluar kegiatan intrakurikuler sebagaimana telah diamanatkan dalam Permendiknas No. 39 tahun 2008 tentang Pembinaan Kesiswaan pasal 3 ayat 1: "Kegiatan ekstrakurikuler bersifat sebagai kegiatan penunjang program intrakurikuler di Madrasah. Sebagai kegiatan penunjang, kegiatan ekstrakurikuler sifatnya tidak mengikat. Keikutsertaan siswa dalam kegiatan ekstrakurikuler yang diprogramkan lebih bergantung pada bakat, minat, dan kebutuhan siswa" (Permendiknas 2008).

Pembinaan siswa yang ada di Madrasah, hendaknya dikembangkan melalui berbagai macam wadah ataupun program yang direalisasikan dengan tujuan untuk menunjang proses pendidikan yang kemudian atas prakarsa sendiri dapat meningkatkan kemampuan, keterampilan ke arah pengetahuan yang lebih maju. Ada banyak wadah pembinaan siswa yang ada di Madrasah, salah satunya yakni kegiatan ekstrakurikuler (Mia Nurdiana dan Ari Prayoga 2018, hlm. 10). Madrasah berupaya untuk merealisasikan, mengembangkan dan membina minat bakat siswa yang ada di Madrasah melalui kegiatan ekstrakurikuler.(Kompri 2015, hlm. 225-226.) Dengan adanya manajemen ekstrakurikuler, maka suatu kegiatan ekstrakurikuler akan dapat dilaksanakan sesuai dengan tujuan yang diharapkan (Qiqi Yuliati Zakiyah dan Ipit Saripatul Munawaroh 2018, hlm. 43). Fungsi manajemen secara umum yang meliputi perencanaan, pelaksanaan, dan evaluasi diterapkan dalam pengelolaan fungsi manajemen ekstrakurikuler.

Kegiatan ekstrakurikuler merupakan suatu kegiatan yang mana didalamnya terdapat wadah perkumpulan bagi peserta didik yang disesuaikan

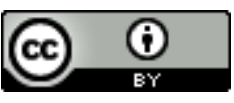




\section{AL-Azkiya: JURHAL LYHAH PEIDIDIKAK YIISD \\ ISSII: Print (2145-1653) Online (2527-8170) \\ Vol. 6 No.2 2021 \\ D01 10.32505/al-akiva.1092.3013}

dengan berbagai minat dan bakat serta kecenderungan peserta didik guna untuk menyalurkan kreativitas dan aktivitas yang dilaksanakan diluar program kegiatan pembelajaran. Craft dalam jurnalnya mengutip Reynold menyatakan bahwa kegiatan ekstrakurikuler dapat meningkatkan kehidupan siswa, ekstrakurikuler juga dapat memberikan siswa keterampilan tambahan yang didapatkandan akan berguna selama sisa hidup mereka (Craft 2012, hlm. 22.)

Kegiatan ekstrakurikuler ini memiliki tujuan dalam pengembangan bakat dan minat peserta didik yang diminatinya, seperti minat dan bakat pada bidang olahraga, kesenian, keterampilan, pramuka, dan lain sebagainya (Syafaruddin 2005, hlm. 265.) Oleh karena itu, untuk mewujudkan kegiatan ekstrakurikuler yang baik maka sangat diperlukan sebuah manajemen untuk mengatur segala proses kegiatan ekstrakurikuler.

Suatu kegiatan ekstrakurikuler dapat dikatakan sukses jika dalam pengembangan bakat dan minat yang dimiliki oleh para peserta didik dapat berkembang secara baik dan mampu memiliki pengetahuan dan wawasan yang luas sehingga nantinya dapat mensupport kegiatan ekstrakurikuler yang ada madrasah tersebut (Saputro, Sukidin, dan Ani 2017, hlm. 50.) Begitu pula sebaliknya, sebuah kegiatan ekstrakurikuler tidak akan sukses jika dalam pengelolaannya tidak dilakukan dengan baik oleh madrasah. Hal ini menguatkan alasan bahwa keefektifan pengelolaan kegiatan ekstrakurikuler menjadi sangat penting karena keberhasilan yang akan dicapai tidak hanya dalam pelaksanaan kegiatannya saja namun juga mendukung keberhasilan dari pendidikan yang ada pada kegiatan ekstrakurikuler. Tujuan pendidikan yang dirancang akan tercapai secara maksimal apabila pengelolaan pendidikan dilaksanakan dengan manajemen yang baik, termasuk di dalamnya kegiatan ekstrakurikuler (Jamaluddin, t.t., hlm. 169.). Berdasarkan beberapa pendapat tersebut di atas, maka dapat disimpulkan bahwa kegiatan ekstrakurikuler adalah kegiatan pelajaran yang dilakukan di luar jam pelajaran biasa yang bertujuan untuk 135

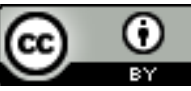


mengembangkan suatu bidang pelajaran sesuai dengan potensi, bakat dan minat peserta didik.

Pelaksanaan Pembinaan dalam mengembangkan kegiatan ekstrakurikuler di sekolah akan memberikan banyak manfaat tidak hanya terhadap siswa tetapi juga bagi efektivitas penyelenggaraan pendidikan di sekolah. Begitu banyak fungsi dan makna kegiatan ekstrakurikuler dalam menunjang tercapainya tujuan pendidikan. Hal ini akan terwujud, manakala pengelolaan kegiatan ekstrakulikuler dilaksanakansebaik-baiknya khususnya pengaturan siswa, peningkatan disiplin siswa dan semuapetugas. Biasanya mengatur siswa di luar jam-jam pelajaran lebih sulit dari mengatur mereka dalam kelas.

Oleh karena itu, pelaksanaan kegiatan ekstrakurikuler melibatkan banyak pihak, memerlukan peningkatan administrasi yang lebih tinggi. Pengembangan ekstrakurikuler dimaksudkan untuk memberikan pengarahan dan pembinaan juga menjaga agar kegiatan tersebut tidak menganggu atau merugikan aktivitas akademis. Yang dimaksud dengan pembina ekstrakurikuler adalah guru atau petugas khusus yang ditunjuk oleh kepala sekolah untuk membina kegiatan esktrakurikuler. Melalui kegiatan ekstrakulikuler peserta didik dapat mengembangkan minat dan bakat yang ada dalam dirinya. agar kegiatan ekstrakulikuler berjalan optimal tentunya diperlukan peran dari seluruh warga sekolah, khusunya kepala sekolah.

Berdasarkan uraian di atas, maka penulis merasa tertarik untuk meneliti tentang Kepemimpinan Kepala Sekolah dalam Pengelolaan Ekstrakurikuler di MI Nahdatul Ulama Sumber Agung agar memiliki kualitas dan daya saing, serta mampu menciptakan sikap-sikap dan tingkah laku sesuai dengan ajaran Islam yang dipraktekkan dalam kehidupan sehari-hari baik di lingkungan sekolah maupun lingkungan keluarga dan masyarakat. 


\section{TINJAUAN TEORITIS}

\section{Kepemimpinan Kepala Sekolah}

Kepemimpinan sebagai kemampuan menggerakkan, memengaruhi, memotivasi, mengarahkan, menasehati, membimbing, menyuruh, memerintah, melarang, dan bahkan menghukum (kalau perlu) serta membina dengan maksud agar manusia sebagai media mau bekerja dalam rangka mencapai tujuan administrasi secara efektif dan efisien (Mulyasa 2005, hlm. 107-108). Selanjutnya, Weshler sebagaimana dikutip oleh Wahjosumidjo menyatakan kepemimpinan sebagai "Leadership is interpersonal influence exercised in asituation and directed, through the communication process, toward the attainment of a specified goal or goals". Menurutnya kepemimpinan adalah pengaruh antara personal yang diuji dalam sebuah situasi dan diarahkan melalui proses komunikasi secara langsung, terhadap pencapaian satu tujuan atau beberapa tujuan (Wahjosumidjo 2013, hlm. 17). Jadi dapat dirumuskan bahwa kepemimpinan adalah kemampuan dan keterampilan untuk meneladani, menuntun, mendorong dan mengarahkan orang lain dalam mencapai suatu tujuan yang telah ditetapkan dan dirumuskan.

Istilah kepemimpinan kepala Madrasah mengandung dua arti yaitukata kepemimpinan sebagai kemampuan atau keterampilan untuk mendorong dan mengarahkan dan membina dalam organisasi yang dipimpinnya. Sedangkan kata kepala Madrasah merupakan personal Madrasah yang bertanggung jawab terhadap seluruh kegiatan-kegiatan Madrasah, Ia mempunyai wewenang dan tanggung jawab penuh untuk menyelenggarakan seluruh kegiatan pendidikan dalam lingkungan Madrasah yang dipimpinnya dengan dasar Pancasila demi tujuan Pendidikan Nasional. 


\section{Ekstrakulikuler}

Peraturan Menteri Pendidikan dan Kebudayaan RI No. 81A tahun 2013 memiliki definisi ekstrakurikuler yakni berbagai macam kegiatan pendidikan yang dilaksanakan oleh peserta didik pada waktu di luar jam pelajaran kurikulum standar sebagai bentuk pengembangan kegiatan kurikulum dan dilaksanakan dengan bimbingan sekolah. Kegiatan ekstrakurikuler memiliki tujuan pengembangan kepribadian, minat, bakat, serta kemampuan peserta didik agar lebih luas atau di luar jam minat yang dikembangkan oleh kurikulum (Peraturan Menteri Pendidikan dan Kebudayaan Republik Indonesia Nomor 81A tahun (2013).

Dalam Peraturan Menteri Pendidikan dan Kebudayaan Republik Indonesia Nomor 81A Tahun 2013 tentang Pelaksanaan Pedoman Kurikuler Kegiatan Ekstrakurikuler mengatur Kegiatan Ekstrakurikuler merupakan kegiatan pendidikan yang dilaksanakan oleh peserta didik di luar standar waktu pembelajaran kurikulum, yakni perluasan kegiatan kurikulum yangdilaksanakan di Madrasah. Tujuannya untuk membina kepribadian, bakat, minat dan kemampuan peserta didik yang memiliki kemampuan belajar lebih atau melebihi kemampuan pengembangan kurikulum (Permendikbud 2003).

Ekstrakurikuler juga mengacu pada kegiatan lain di luar perencanaan kurikulum atau pendidikan lain di luar kurikulum. Menurut Farida Yusuf bahwa ekstrakurikuler merupakan kegiatan pembelajaran yang dilaksanakan pada luar jam sekolah pokok (Suryosubroto 2002, hlm. 271). Bartkus mendefinisikan kegiatan ekstrakurikuler sebagai kegiatan akademik atau non-akademik yang dilakukan di bawah naungan sekolah tetapi terjadi di luar kebiasaan waktu kelas dan bukan bagian dari kurikulum, tidak melibatkan nilai atau kredit akademik dan partisipasi merupakan pilihan bebas yang diberikan pada siswa (Bartkus dkk. 2012). 
Kesimpulan yang dapat ditarik dari beberapa pendapat yang dikemukakan bahwa kegiatan ekstrakurikuler merupakan suatu kegiatan pembelajaran yang dilaksanakan pada luar jam kelas reguler dirancang untuk mengembangkan mata pelajaran berdasarkan potensi, bakat dan minat siswa.

Ekstrakurikuler dirancang untuk mengembangkan satu set bidang mata pelajaran yang menarik bagi siswa, seperti olahraga, seni, berbagai keterampilan, dan kepramukaan (Suryosubroto 2002, 271). Rusman percaya bahwa tujuan utama kegiatan ekstrakurikuler adalah untuk memberikan ruang kepada siswa berupa pengalaman yang sesuai dengan minat, hobi bakat dan kemampuan yang dimiliki siswa (Rusman 2011, hlm. 20). Partisipasi dalam kegiatan ekstrakurikuler berbasis sekolah seperti olah raga, kesenian, dan klub akademik, memberikan peluang bagi perkembangan siswa baik secara pendidikan maupun perkembangan mentalnya (Mahoney, Harris, dan Eccles 2006, hlm. 3.).

Sudah banyak studi yang menunjukkan hubungan positif antara berpartisipasi dalam olahraga sepulang sekolah atau kegiatan organisasi dan nilai rata-rata akhir siswa. Mahoney dkk menyatakan bahwa partisipasi aktivitas remaja telah ditemukan terkait dengan pencapaian pendidikan yang lebih tinggi, dan prestasi mengurangi perilaku bermasalah dan kompetensi psikososial yang tinggi (Abruzzo dkk. 2016, hlm. 21.).

\section{METODE PENELTTIAN}

Metode penelitian yang digunakan dalam penelitian ini adalah pendekatan kualitatif. Instrumen penelitian yang digunakan yaitu obervasi dan wawancara. Obervasi dilakukan di MI Nahdatul Ulama Sumber Agung, Kec. Buay Madang, Kab. OKU Timur, Sumatera Selatan. Observasi yang digunakan ialah observation non-participant. Wawancara dilakukan dengan kepala sekolah yang berinisial SP, dewan guru, dan peserta didik. Penelitian dilakukan pada 2-6 Maret 2021.

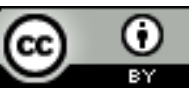


Teknis analisis data yang digunakan adalah 1) reduksi data, data-data yang telah diperoleh akan dipilih dan dipusatkan pada fokus penelitian yaitu bagaimana kepemimpinan kepala sekolah dalam mengelola ekstrakulikuler. 2) Penyajian data, data yang sudah melewati proses proses reduksi selanjutnya adalah penyajian data, sehingga data dapat tersusun dalam pola hubungan, sehingga akan semakin mudah untuk dipahami. 3) Penarikan kesimpulan, setelah data disajikan selanjutnya akan ditarik kesimpulan terkait kepemimpinan kepala sekolah dalam pengelolaan ekstrakulikuler.

\section{HASIL DAN PEMBAHASAN}

Ekstrakurikuler merupakan kegiatan belajar diluar jam pelajaran yang bisa dijadikan wadah untuk mengasah minat dan bakat siswa. Hal ini menjadi perhatian penting kepala sekolah, mengingat selain aspek kognitif dan afektif, aspek psikomotorik anak juga perlu dikembangkan. Di MI Nahdatul Ulama Sumber Agung, Kec. Buay Madang, Kab. OKU Timur, Sumatera Selatan juga menyajikan beberapa pilihan ekstrakurikuler yang bisa diikuti oleh siswasiswinya, seperti ektrakurikuler pramukan, muhadhoroh, puisi, menari, badminton, volly, sepak bola. Ekstrakurikuler tersebut disajikan agar anak memilih minat dan bakat yang ingin mereka kembangkan. Dalam hal ini, kepala sekolah memiliki peranan penting dalam pengelolaannya, seperti merencanakan/merumuskan, mengadakan, serta mengevaluasi dan mengontrol jalannya ekstrakurikuler.

Kepala sekolah di MI Nahdatul Ulama Sumber Agung, Kec. Buay Madang, Kab. OKU Timur, Sumatera Selatan membuat rumusan ekstrakurikuler dengan memberikan tawaran-tawaran berupa angket yang diisi oleh siswa, dari angket tersebut dihasilkan jenis ekstrakurikuler yang sesuai dengan minat dan bakat anak. Setelah itu baru membentuk divisi-divisi yang diketuai oleh seorang guru pembina. Kemudian kepala sekolah dan guru pembina mencari pihak yang ahli

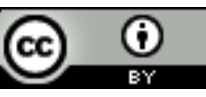


dalam bidang ekstrakurikuler tertentu. Setelah diputuskan tim pelaksana, maka hal selanjutnya adalah memenuhi sarana dan prasarana yang dibutuhkan untuk kegiatan ekstrakurikuler.

Selain sarana dan prasarana, insentif juga dikalkulasi untuk diberikan kepada kepala divisi dan pembimbing ekstrakurikuler tersebut. Dalam setiap perjalanan ekstrakurikuler, kepala sekolah akan mengadakan evaluasi tentang kekurangan dan juga kendala yang terjadi selama berlangsungnya kegiatan. Hasil evaluasi ini lah yang akan menentukan keputusan dan juga tindakan yang akan diambil untuk perbaikan di waktu selanjutnya.

Kepala sekolah di bawah kepemimpinannya melakukan kontrol penuh atas semua kegiatan ekstrakurikuler di MI Nahdatul Ulama Sumber Agung, Kec. Buay Mada ng, Kab. OKU Timur, Sumatera Selatan. Kontrol diperlukan agar tujuan dan visi misi dari kegiatan ekstrakurikuler tersebut dapat tercapai. Dalam setiap proses kegiatan kepemimpinan, tak jarang kepala sekolah menemukan kendalakendala yang mempengaruhi kegiatan ekstrakurikuler. Seperti: 1) Kendala mendapatkan pembimbing yang ahli dalam kegiatan ekstrakurikuler yang bisa menyesuaikan waktu dengan waktu yang sudah disediakan sekolah. 2) Kendala dalam membeli anak panah yang harganya mahal dan hanya bisa dipakai bebrapa kali saja. 3) Kendala juga kadang muncul pada sulitnya menanamkan motivasi kepada anak yang kurang memiliki minat dan bakat sehingga tidak bersemangat dalam mengikuti kegiatan ekstrakurikuler.

Sejauh ini kepemimpinan kepala sekolah dalam mengelola ekstrakurikuler di MI Nahdatul Ulama Sumber Agung, Kec. Buay Madang, Kab. OKU Timur, Sumatera Selatan merasa telah mendapat hasil yang cukup memuaskan. Hal tersebut ditunjukkan dengan minat dan bakat peserta didik lewat kegiatan ekstrakurikuler bisa ikut ditampilkan dalam perlombaan tingkat sekolah, kecamatan, maupun tingkat kabupaten.

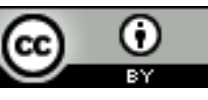




\section{AL-Azkiya: JURHAL LYHAH PEIDIDIKAK YIISD \\ ISSII: Print (2145-1656) Online (2521-8170) \\ Vol. 6 No.2 2021 \\ D01 10.32505/al-akiva.1092.3013}

\section{KESIMPULAN}

Ekstrakurikuler memiliki andil dalam mengasah bakat dan minat peserta didik di MI Nahdatul Ulama Sumber Agung, Kec. Buay Madang, Kab. OKU Timur, Sumatera Selatan. Untuk mencapai keberhasilan tujuan ekstrakurikuler di MI Nahdatul Ulama Sumber Agung, kepala sekolah memiliki peran penting dalam pengelolaannya, mulai dari perencanaan, pengadaan, evaluasi, dan juga kontrol dalam setiap jalannya ekstrakurikuler. Kendala yang dihadapi dalam pengelolaan ekstrakurikuler adalah sulitnya mendapatkan pembimbing yang kompeten sesuai bidang, kadang sulit mendapatkan prasarana, dan juga kendala dalam memotivasi peserta didik agar terus bersemangat mengikuti kegiatan. Hasil yang dicapai yang merupakan bagian dari keberhasilan pengelolaan ekstrakurikuler adalah minat dan bakat siswa bisa diikutsertakan dalam perlombaan.

\section{DAFTAR PUSTAKA}

Abruzzo, Kristen J., Cristina Lenis, Yansi V. Romero, Kevin J. Maser, dan ElsaSofia Morote. 2016. "Does Participation in Extracurricular Activities Impact Student Achievement?" Journal for Leadership and Instruction 15 (1): 2126.

Astafiyah, Astafiyah. 2018a. "Kontribusi Efektivitas Manajemen Ekstrakurikuler Terhadap Prestasi Sekolah Non Akademik." Tarbawi: Jurnal Keilmuan Manajemen Pendidikan 4 (02).

- - - 2018b. "Kontribusi Efektivitas Manajemen Ekstrakurikuler Terhadap Prestasi Sekolah Non Akademik." Tarbawi: Jurnal Keilmuan Manajemen Pendidikan 4 (02): 263-74.

Bartkus, Kenneth R., Blake Nemelka, Mark Nemelka, dan Phil Gardner. 2012. "Clarifying The Meaning Of Extracurricular Activity: A Literature Review Of Definitions." American Journal of Business Education (AJBE) 5 (6): 693704.

Craft, Steven Wesley. t.t. "The Impact of Extracurricular Activities on Student Achievement at the High School Level," 94.

Indah Nur Aini Putri, Heru Santoso. 2020. "Manajemen Kegiatan Ekstrakulikuler Robotik Di SMA Negeri 28 Jakarta." Jurnal Improvement 7 (1).

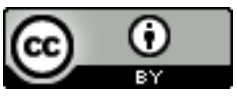




\section{AL-Azkiya: JURHAL LYHAH PEIDIDIKAK YIISD \\ ISSI: Print (2145-1653) Online (2521-8170) \\ Vol. 6 No.2 2021 \\ D01 10.32505/al-akiva.1092.3013}

Jamaluddin. t.t. "Manajemen Ekstrakulilkuler Madrasah Aliyah." JIEM (Journal of Islamic Education Manajemen) Vol. 3 (2).

Kompri. 2015. Manajemen Pendidikan. Yogyakarta: Ar-Ruzz Media.

Mahoney, Joseph L., Angel L. Harris, dan Jacquelynne S. Eccles. 2006. “Organized Activity Participation, Positive Youth Development, and the OverScheduling Hypothesis." Social Policy Report 20 (4): 1-32.

Mulyasa, E. 2005. Manajemen Berbasis Sekolah. Bandung: Remaja Rosdakarya.

Nurdiana, Mia, dan Ari Prayoga. 2018. "Fungsi-Fungsi Manajemen dalam Kegiatan Ekstrakurikuler Pramuka di Madrasah." Madrasa: Journal of Islamic Educational Management 1 (Desember): 9-15.

Peraturan Menteri Pendidikan dan Kebudayaan Republik Indonesia Nomor 81A tahun (2013). 2013.

Permendikbud. 2003. Permendikbud, Nomor 81A Tahun 2003 tentang Implementasi Kurikulum Pedoman Kegiatan Ekstrakurikuler.

Permendiknas. 2008. Permendiknas No. 39 tahun 2008 Tentang Pembinaan Kesiswaan Pasal 3 Ayat 1.

Rusman. 2011. Manajemen Kurikulum. Jakarta: Rajawali Press.

Saputro, Ruliyanto Ratno, S. Sukidin, dan Hety Mustika Ani. 2017. "Manajemen Ekstrakurikuler Non-Akademik Siswa Di SMA Muhammadiyah 3 Jember." Jurnal Edukasi 4 (3): 49-53.

Suryosubroto. 2002. Proses Belajar Mengajar di Sekolah. Jakarta: Rineka Cipta.

Syafaruddin. 2005. Manajemen Lembaga Pendidikan Islam. Jakarta: Ciputat Press.

Wahjosumidjo. 2013. Kepemimpinan Kepala Sekolah: Tinjauan Teoretik dan Permasalahannya. 9 ed. Jakarta: PT Raja Grafindo Persada.

Zakiyah, Qiqi Yuliati, dan Ipit Saripatul Munawaroh. 2018. "Manajemen Ekstrakurikuler Madrasah." Jurnal Isema: Islamic Educational Management 3 (1). 